\title{
THE EVALUATION OF GRAIN SHEAR STRESS FROM EXPERIMENTS IN A PEBBLE-BEDDED FLUME
}

\author{
DR. FRANÇOIS PETIT \\ Laboratory of Physical Geography, University of Liège, Belgium
}

Received 10 July 1988

Revised 3 February 1989

\begin{abstract}
Initial experiments were conducted in a flat-bottomed flume with pebbles (median diameter slightly below $20 \mathrm{~mm}$ ), with a view to test the validity of the methods which permit differentiation between shear stress due to grain resistance $\left(\tau^{\prime}\right)$ and that due to bedform resistance $\left(\tau^{\prime \prime}\right)$. It is clearly confirmed that $\tau^{\prime}$ represents the total shear stress $(\tau)$. The method of Laursen (1958) is appropriate for evaluation of grain shear stress in the case of pebbly beds. Indeed the ratio $\tau^{\prime} / \tau$ is close to 1 , except when the dimensionless flow depth $\left(d / D_{50}\right)$ is less than 4 . A close relationship exists between the grain shear stress and the shear stress calculated from friction velocities.

A second series of experiments was then carried out in the same flume, after creating differences in bedform (alternating riffles and pools). The ratio $\tau^{\prime} / \tau$ produced by Laursen's method represents on average $0 \cdot 40$. The relationship between these grain shear stresses and the shear stresses calculated from shear velocities is relatively good here as well, and is similar in presentation to that established in the case of flat bed. Finally, as confirmation of the adequacy of Laursen's method under the same initial conditions of bottom slope and discharge, the grain shear stress for an undulating bed is very close to the total shear stress of a flat bed.
\end{abstract}

KEY WORDS Flume experiments Pebbly bed Shear stress Grain roughness Bedform roughness

\section{INTRODUCTION}

It is becoming increasingly apparent in recent works on river dynamics that shear stress is the most reliable parameter in explaining movement and transport of bedload (Lisle, 1979; Dietrich et al., 1979; Bridge and Jarvis, 1982; Leopold and Emett, 1981; Petit, 1987).

Nonetheless it emerges from the initial works of Einstein and Barbarossa (1952) that shear stress in the case of natural rivers, comprises two parts: a shear stress $\tau^{\prime}$ due to the resistance of particles forming the bed and an additional shear stress $\tau^{\prime \prime}$ due to irregularities of the channel bed and banks, i.e. the bedform. In principle it is solely that shear stress due to particle resistance which should be taken into account for the movement of particles. The distinction between shear stress now seems to be fully accepted not only in the case of flumes or natural rivers (Hey, 1979; Singhal et al., 1980; Carling, 1983; Kapdasli and Dyer, 1986), but also in respect of overland flow on irregular surfaces (Govers and Rauws, 1986).

Several methods have been suggested to differentiate the two components of the total shear stress. Some of these methods have been tested in particular in a sandy-bedded flume (Singhal et al., 1980) or applied in the case of a natural river (Carling, 1983). However the evaluation of the grain shear stress for different types of natural rivers has yielded values which are clearly insufficient to account for the erosion of material actually witnessed (Petit, 1989). Conversely the evaluation of shear stress from friction velocities - using the redefined parameter of roughness $y_{1}$ - enabled most of the geomorphological modifications to be explained. 
Therefore, a series of flume experiments was undertaken in order to test, in the case of pebbly beds, the various methods capable of distinguishing between grain shear stress and bedform shear stress. The first experiments were conducted with a flat bed without differentiation of bedform, where, consequently bedform resistance was nil and where, in theory, the application of the proposed methods is expected to produce grain shear stress equal to total shear stress. In the second stage, differences of bedform were created in the flume and the grain shear stresses are determined by means of the methods tested in the flat bed. But, contrary to Singhal et al. (1980), it was not possible in this study to use the bed sediment discharge as verification of the same grain shear stress for flat bed and undulating bed, because other parameters influence the motion of pebbles (shape of pebbles, imbrication, protrusion, ....). This is why shear stresses are also calculated from friction velocities and compared with the grain shear stress in both the cases.

\section{FLUME CHARACTERISTICS}

The experiments were conducted in a flume placed at our disposal by the Department of Physical Geography of the University of Uppsala (Sweden). Its working length is $6 \mathrm{~m}$, its width $0.5 \mathrm{~m}$; its longitudinal gradient may vary from $0 \%$ to $35 \%$ and the adjustable discharge can reach $0.4 \mathrm{~m}^{3} \mathrm{~s}^{-1}$. By means of a pointer mounted on a mobile trolley, the altimetric dimensions can be precisely determined for any point in the flume, thus permitting the measurement of depth, transverse sections, and also longitudinal and transverse gradients of the water plane. Flow velocities were measured by an OTT meter (OTT C2) fitted with $3 \mathrm{~cm}$ diameter propellers and by an electromagnetic probe which permits instantaneous velocity measurement and recording even at $10 \mathrm{~mm}$ from the bottom of the bed.

During the first series of experiments with a flat bed, the bottom of the flume was composed of granite pebbles stuck in place. The $\mathrm{D}_{50}$ of the material was $19.6 \mathrm{~mm}$ with the following granulometric features:

$$
\mathrm{D}_{90}=28.5 \mathrm{~mm} ; \quad \mathrm{D}_{75}=23.0 \mathrm{~mm} ; \quad \mathrm{D}_{64}=21.2 \mathrm{~mm}
$$

In the second stage, modifications of the bedform were carried out as follows: the upstream section flume was loaded with movable material of identical composition and granulometric characteristics. Discharge was then progressively increased until movement of the pebbly material was initiated. Pebbly accumulations built up downstream at relatively regular intervals (at $2.6 \mathrm{~m}, 3.5 \mathrm{~m}$, and $4.6 \mathrm{~m}$ ) forming a succession of alternating riffles and pools, the altimetric differences between high and low points being of the order of $40 \mathrm{~mm}$. Subsequent work was conducted with dynamic conditions (gradient and discharge) slightly below those which had brought about the fashioning of these bedforms.

\section{STUDY METHODS}

The side wall friction was corrected according to the procedure proposed by Johnson (1942) and modified by Vanoni and Brooks (in Vanoni, 1975).

Shear stress was determined by the two standard approaches, the one involving the water surface slope $(S)$ and the hydraulic radius with respect to bed $\left(R_{b}\right)$ :

$$
\tau=\gamma R_{b} S
$$

where $\gamma$ : the specific weight of the fluid; and the other involving shear velocities $\left(u_{*}\right)$ using Equations 2 and 2.1

with

$$
\tau=\rho u_{*}^{2}
$$

$$
\frac{u}{u_{*}}=\frac{1}{\kappa} \ln \frac{y}{y_{1}}
$$

where $\rho=$ density of the fluid

$u=$ velocity measured at height $y$ above the bed

$\kappa=$ Von Karman's constant

$y_{1}=$ parameter of roughness. 
The virtual bottom of the bed is $0.7 \mathrm{D}_{90}$ above the plane where the particles are fixed, in agreement with results of Kamphuis (1974) and very close to Komar and $\mathrm{Li}$ (1988).

The $y_{1}$ parameter was evaluated during an early series of experiments from analysis of velocity gradient in close proximity of the bottom (Petit, 1988). This method is used for flumes (Meland and Norrman, 1966) and for natural rivers (Dietrich et al., 1979; Bridge and Jarvis, 1982). The velocities $u$ are plotted against $\log y$ and a straight line is drawn from the points located in the lowest part of the flow; the height of interception on the yaxis gives the roughness height $y_{1}$. This parameter was evaluated from 38 velocity profiles measured at different places in the flume for a range of different discharges and slopes. The mean values $\left(y_{1}=1.8 \mathrm{~mm}\right)$ is very close to that obtained from the equation proposed by Kamphuis (1974) where $y_{1}=k_{s} / 30$ ( $k_{s}=$ Nikuradse's sand grain roughness) and $k_{s}=2 \mathrm{D}_{90}$.

The separation of total shear stress between grain shear stress $\left(\tau^{\prime}\right)$ and that due to bedform resistance $\left(\tau^{\prime \prime}\right)$ was implemented using three methods. The first is based on the difference in roughness coefficients in Manning's formula (in Richards, 1982):

$$
\tau^{\prime}=\tau . K^{3 / 2}
$$

where $K=n^{\prime} / n_{0}$

with $\quad n_{0}=$ the total roughness coefficient in Manning's formula;

$n^{\prime}=$ Manning's roughness coefficient due solely to grain roughness, obtainable from Strickler's formula.

In literature, different forms of the Stickler formula have been proposed:

$$
\begin{aligned}
& n^{\prime}=0.048 \mathrm{D}_{50}^{1 / 6} \\
& n^{\prime}=0.038 \mathrm{D}_{90}^{1 / 6} \\
& n^{\prime}=0.041 \mathrm{D}_{50}^{1 / 6} \\
& n^{\prime}=0.047 \mathrm{D}_{75}^{1 / 6}
\end{aligned}
$$

In all these equations, $\mathrm{D}$ is expressed in metres.

Equations 3.1 (Richards, 1982) and 3.4 (Lane and Carlston in Simons and Senturk, 1977) are developed for pebble-bedded streams while Equations 3.2 (Simons and Senturk, 1977) and 3.3 (Bray, 1979) tend to underestimated $n^{\prime}$ in gravel bed rivers (Bray, 1979).

The second method used in order to separate grain shear stress and bedform shear stress, was developed by Laursen (1958):

$$
\bar{u}=\frac{21 \cdot 1 R^{\prime 2 / 3} S^{1 / 2}}{k_{s}^{1 / 6}}
$$

where $\bar{u}=$ mean velocity

$k_{s}=$ roughness parameter considered equal to $\mathrm{D}_{50}$

$S=$ slope.

Resolution of this equation gives $R^{\prime}$, the contribution of the hydraulic radius solely due to grain resistance. Knowledge of $R^{\prime}$ enables $\tau^{\prime}$ to be deduced by applying an equation similar to Equation 1 .

A third approach was developed by Meyer-Peter and Muller (in Singhal et al., 1980). They considered that the energy slope $S$ is divided into two parts: the one, $S^{\prime}$, being necessary to overcome particle resistance, the other, $S^{\prime \prime}$ to overcome bedform resistance. The value of $S^{\prime}$ can be calculated from the following equation:

$$
\frac{\bar{u}}{\sqrt{ } g R_{b} S^{\prime}}=5.75 \log \frac{12 \cdot 27 R_{b} x}{k_{s}}
$$

where $\bar{u}=$ mean velocity

$R_{b}=$ hydraulic radius with respect to bed

$k_{s}=$ roughness parameter considered equal to $\mathrm{D}_{50}$

$x=$ correction factor, generally equal to 1 (Bogardi, 1974).

Knowing $S^{\prime}$, one can then calculate $\tau^{\prime}$ by applying Equation 1 . 


\section{RESULTS}

Flat bed

Preliminary experiments were conducted in the flume without bedforms in order to test the agreement between shear stress calculated from slope gradient and hydraulic radius (Equation 1) and from the shear velocities (Equations 2 and 2.1). For these latter, each point is given by the average of 9 values of shear stresses evaluated from velocity profiles made by regular steps in width across the flume section. The straight line produced by regression $(r=0.974)$ is not far from the line of perfect agreement (Figure 1). However the shear stresses evaluated from the shear velocities tend to be more important, systematical divergence becoming evident for the highest values (more than $25 \mathrm{Nm}^{-2}$ ).

We then applied Equations 4 and 5 to the flat bed as to confirm the validity of these methods and grain shear stresses are compared with the total shear stresses calculated from Equation 1 (Figure 2). Values produced by the Laursen method (Equation 4) are very close to the total shear stress while the values

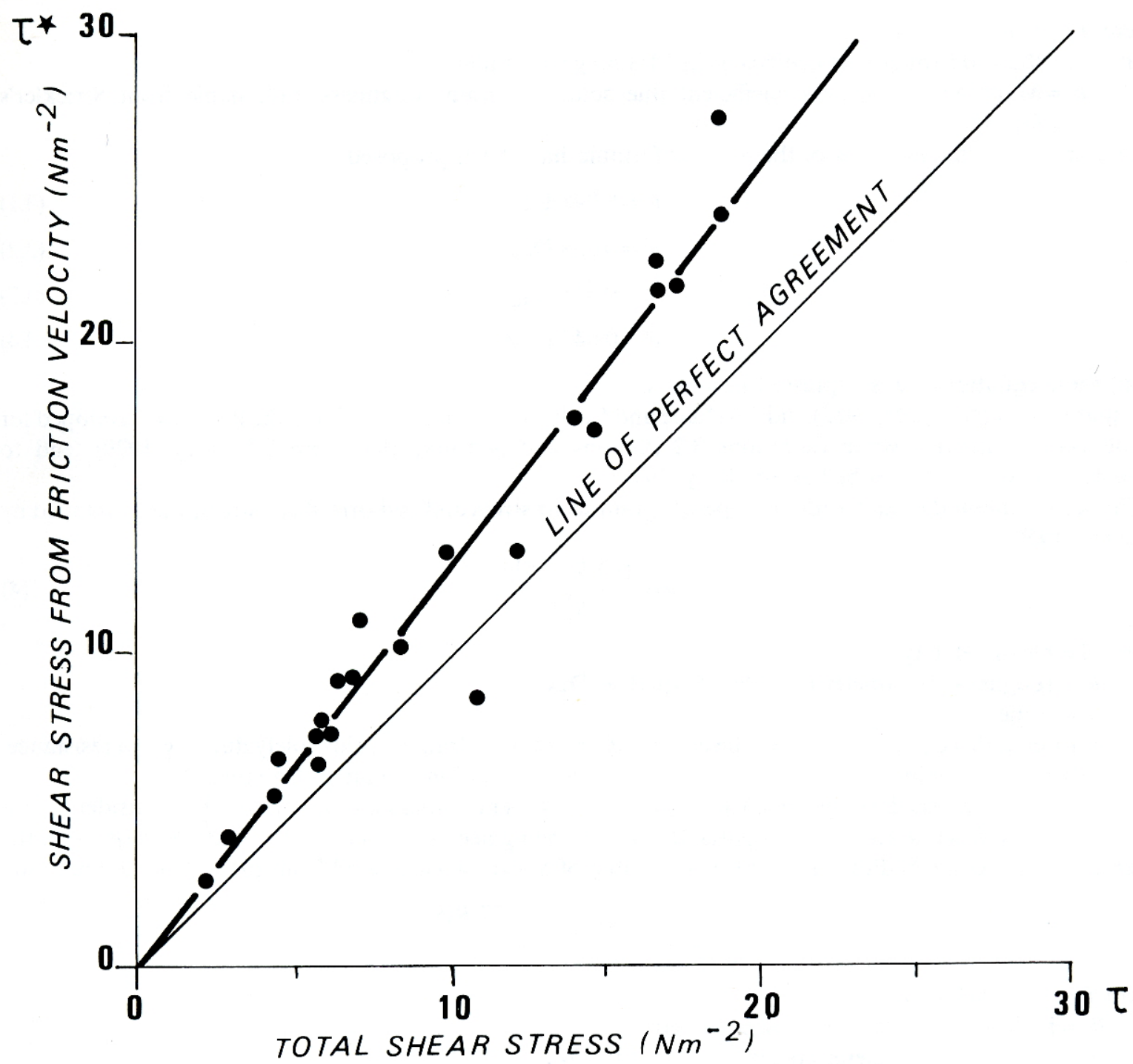

Figure 1. Relation for a flat bed between the total shear stress calculated from the slope and the hydraulic radius ( $\tau$ ) (Equation 1), and the shear stress evaluated from shear velocities $\left(\tau^{*}\right)$ (Equation 2$)$ 


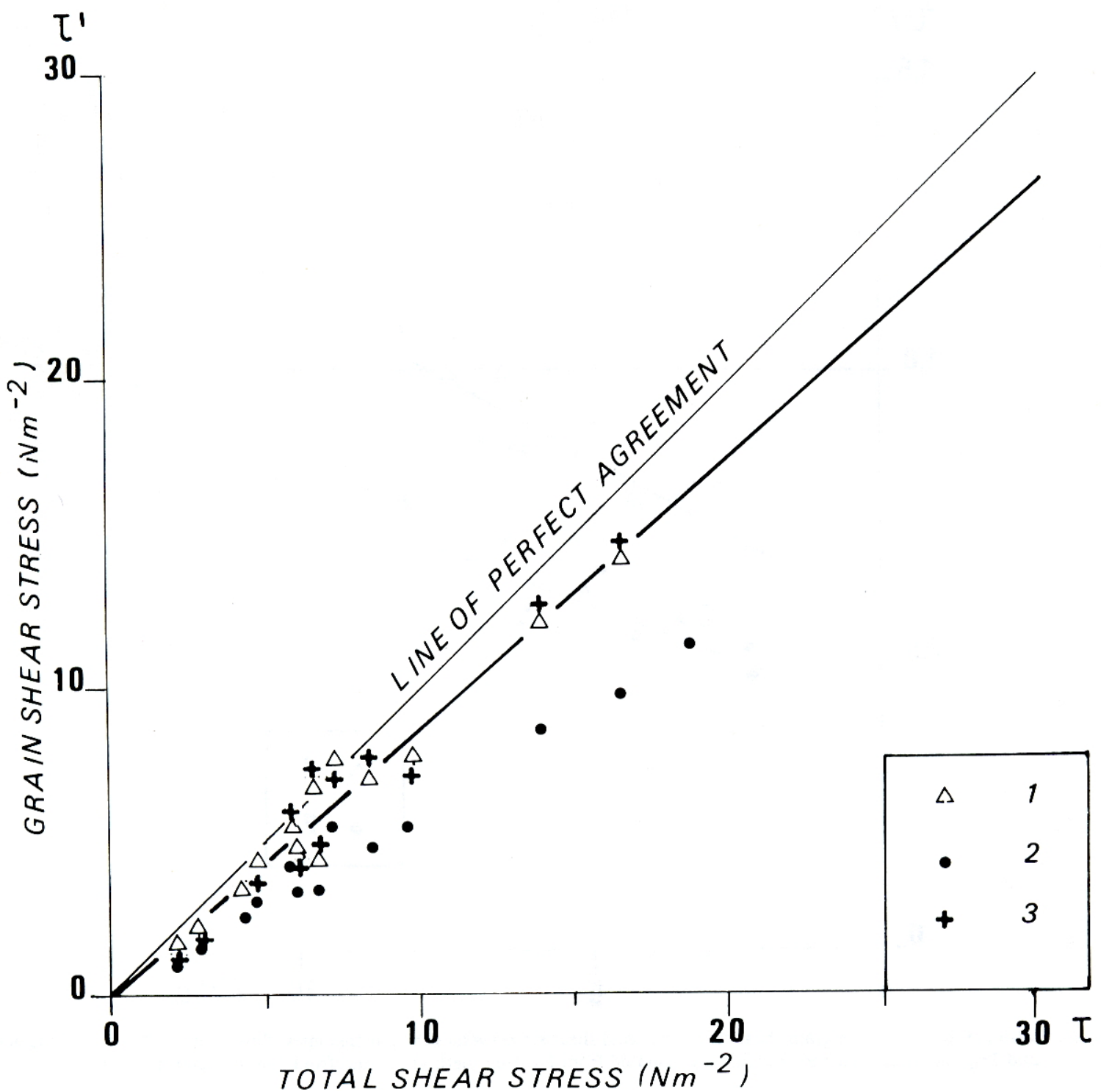

Figure 2. Relation for a flat bed between the total shear stress calculated from the slope and the hydraulic radius $(\tau)$ (Equation 1$)$ and the grain shear stress $\tau^{\prime}$ evaluated from Laursen method (1), Meyer-Peter method (2), and (3) using the ratio $n^{\prime} / n_{o}$ in Equation 3

calculated from Meyer-Peter equation undervalue systematically. In agreement with Singhal et al. (1980), the Laursen method seems to be more adequate.

On the other hand, it confirms that the bedform shear stress is very low in the case of beds without differentiations of bedforms and thus that the ratio $\tau^{\prime} / \tau$ is close to 1, except when the depth is small (Figure 3). In that case, Manning's $n_{0}$ is significantly greater $\left(n_{0}=0.030\right)$ than $n^{\prime}$ deducted using Strickler's formula, $n^{\prime}$ varying from 0.021 to 0.025 following the Equations 3.1 to 3.4 (see below for discussion and Figure 4).

The determination of grain shear stresses using Equation 3 with a Strickler's coefficient $n^{\prime}$ equal to 0.025, gives results very close to those from the Laursen method, which are not far from the line of agreement with the total shear stress (Figure 2). However, the use of this method is subject to uncertainty about the choice of the $n^{\prime}$ value. In this case, Equations 3.1 and 3.4 are applied because they are developed for beds with cobbles, while the Equations 3.2 and 3.3 yield $n^{\prime}=0.021$. 


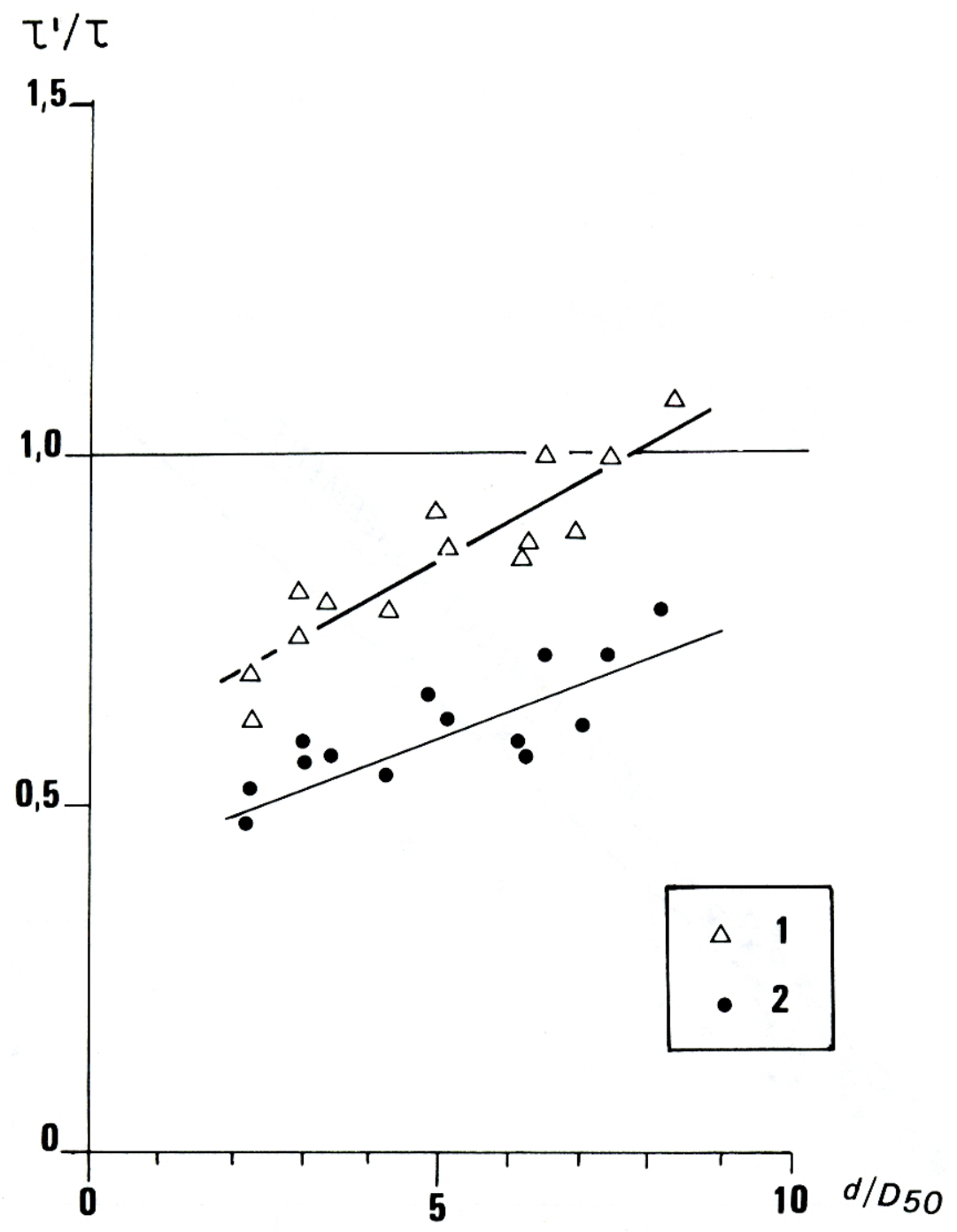

Figure 3. Ratio $\tau^{\prime} / \tau$ (ratio between grain shear stress and total shear stress) versus the dimensionless flow depth $d / \mathrm{D}_{50}$ (with $d$ the depth and $\mathrm{D}_{50}$ the median diameter), with $\tau^{\prime}$ calculated from Laursen method (1), and from Meyer-Peter method (2)

\section{Undulating bed}

Total shear stresses were first calculated by means of Equation 1 and are compared with the shear stress obtained from friction velocities (Equations 2 and 2.1). For these latters, each point means the average of 18 values measured at different places along the flume (on the riffles and the pools). Figure 5 shows that the total shear stress is much higher than the shear stress deducted from the shear velocities. This differs clearly from what was shown for the flat bed where shear stress calculated from friction velocities was slightly higher than the total shear stress.

When the grain shear stress is calculated, Laursen's method (Equation 4) gives a mean ratio $\tau^{\prime} / \tau$ of $0 \cdot 40$ with values varying from 0.31 to 0.46 , while Meyer-Peter's method (Equation 5) yields a ratio of 0.22 with extremes of 0.16 and 0.26 . Of course, the value of Manning's $n_{0}$ is significantly higher for the undulating bed: it exceeds 0.052 for small value of dimensionless flow depth but remains higher than 0.040 for more important depths. By application of Equation 3, this results in a mean ratio $\tau^{\prime} / \tau$ of 0.40 , with extremes of 0.31 and 0.47 , almost equal to the values of provided by Lauren's method.

When these grain shear stresses are compared with shear stresses calculated from friction velocities, it is found that the regression line $(r=0.967)$ is, for Laursen's method, not close - although parallel-to the line of 


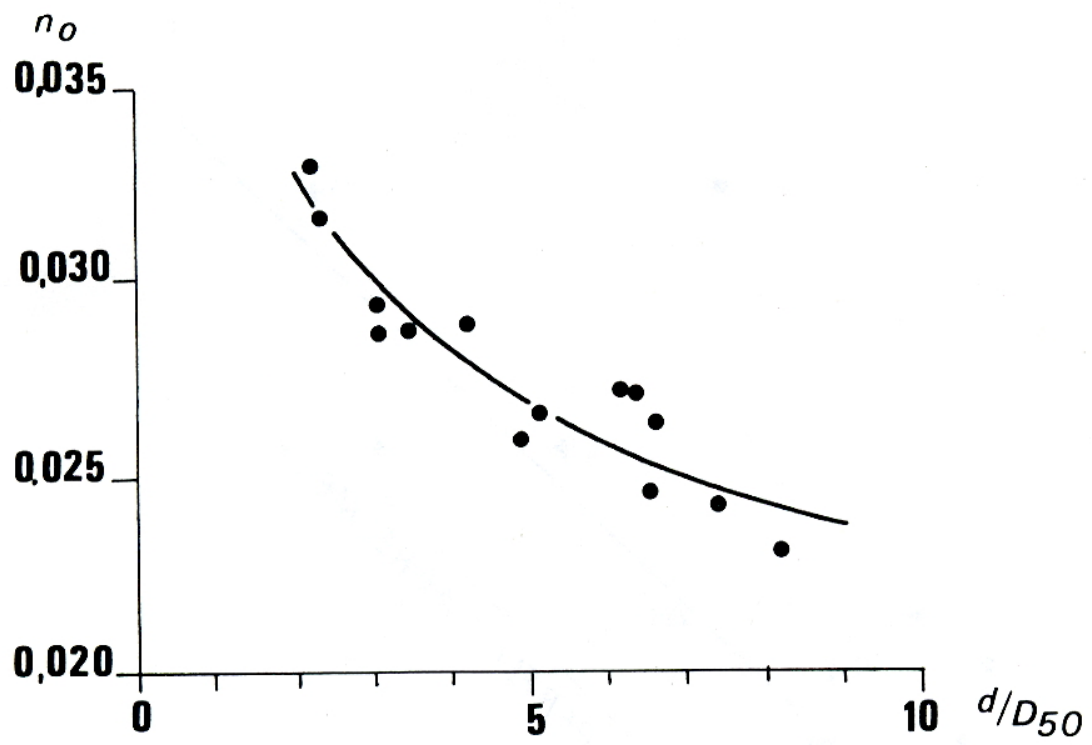

Figure 4. Values of the total roughness coefficient of Manning $\left(n_{0}\right)$ for a flat bed according to the dimensionless flow depth (ratio $\left.d / \mathrm{D}_{50}\right)$

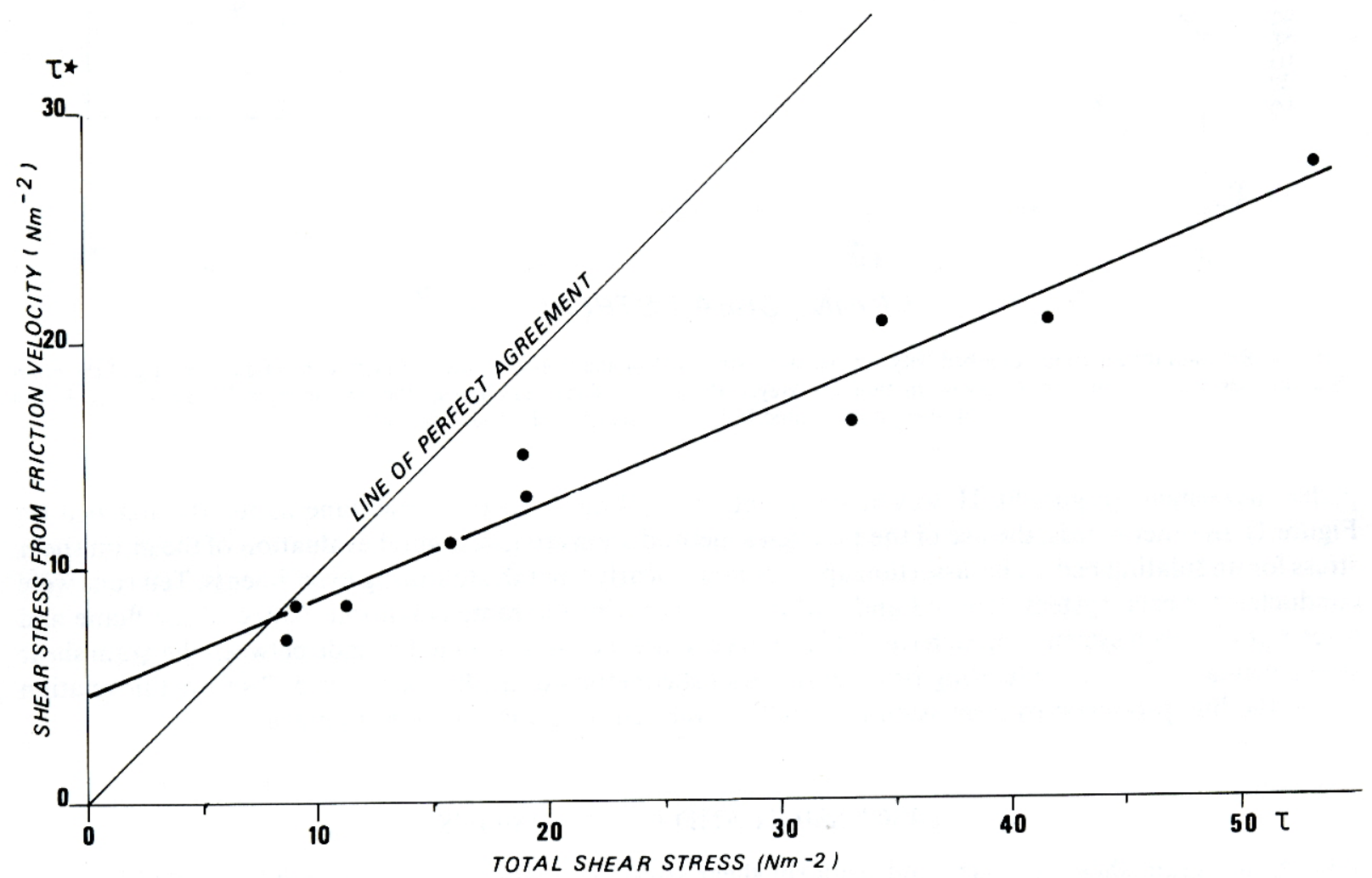

Figure 5. Relation for an undulating bed between the total shear stress calculated from slope and hydraulic radius $(\tau)$ (Equation 1$)$ and the shear stress evaluated from shear velocities $\left(\tau^{*}\right)$ (Equation 2$)$ 


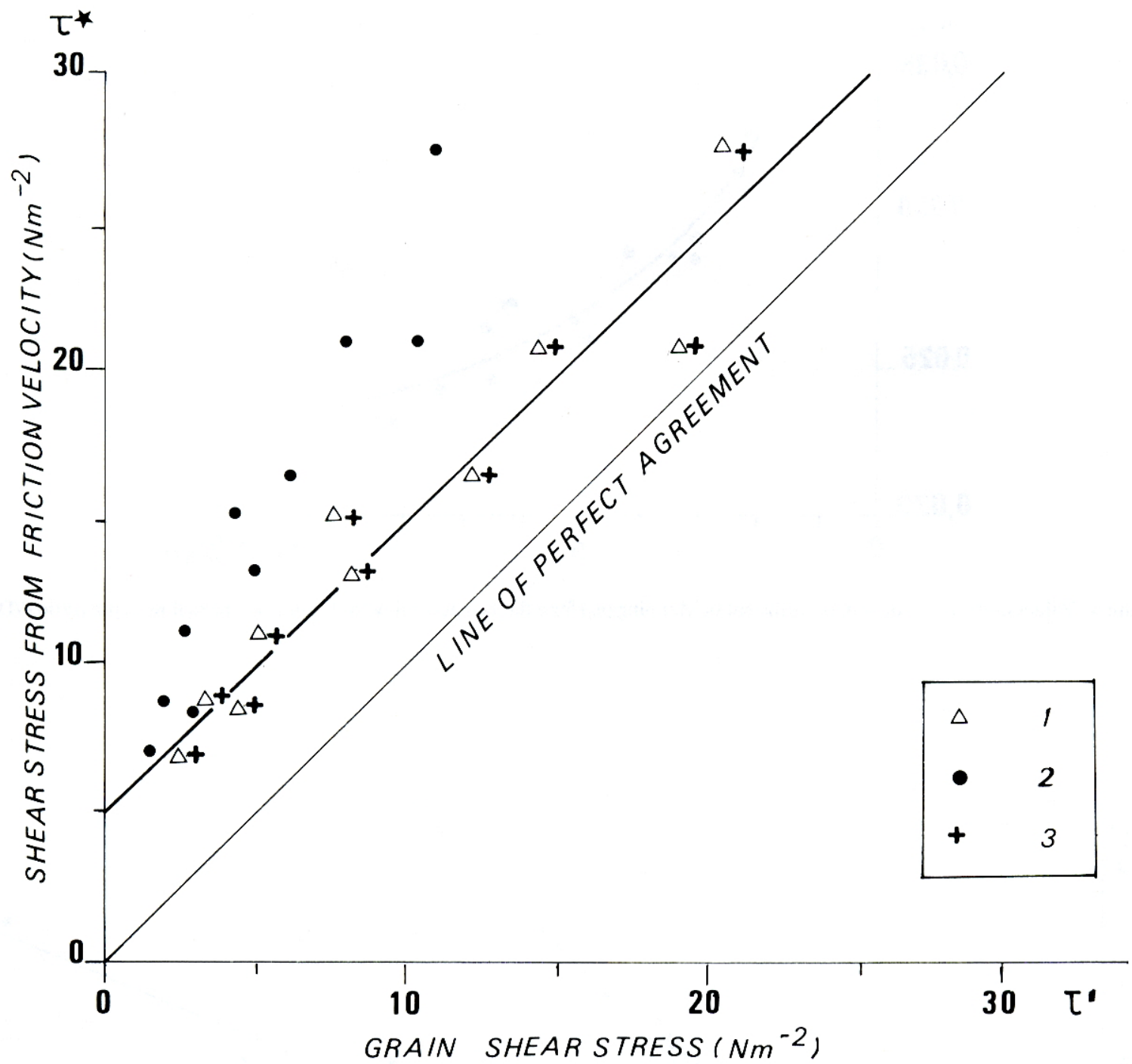

Figure 6. Relation for an undulating bed between the shear stress calculated from the shear velocities $\left(\tau^{*}\right)$ (Equation 2$)$ and the grain shear stresses $\tau^{\prime}$ calculated from Laursen's method (1), Meyer-Peter method (2) and (3) using the ratio $n^{\prime} / n_{0}$ in Equation 3; the line of regression is calculated from $\tau^{\prime}$ evaluated by Laursen method

perfect agreement (Figure 6). However, the points plotted occur in the same zone as for the flat bed (in Figure 1). In other words, the use of the Laursen's method seems to give a good evaluation of the grain shear stress for undulating beds. This assertion appears more clearly from the following experiments. Ten runs were conducted for each system (flat bed and undulating bed) with the same conditions (slope of the flume and discharge) for both systems on each run. This enabled a direct comparison to be made between the grain shear stress evaluated for the undulating bed and the total shear stress of the flat bed. Figure 7 shows this relation where the line produced by regression $(r=0.938)$ is very close to the line of agreement.

\section{DISCUSSION AND CONCLUSIONS}

To evaluate grain shear stress $\left(\tau^{\prime}\right)$ and bedform shear stress $\left(\tau^{\prime \prime}\right)$, various methods were first tested in a flatbedded flume. It emerges from the experiments that the Laursen method is well suited, the $\tau^{\prime}$ being close to the 


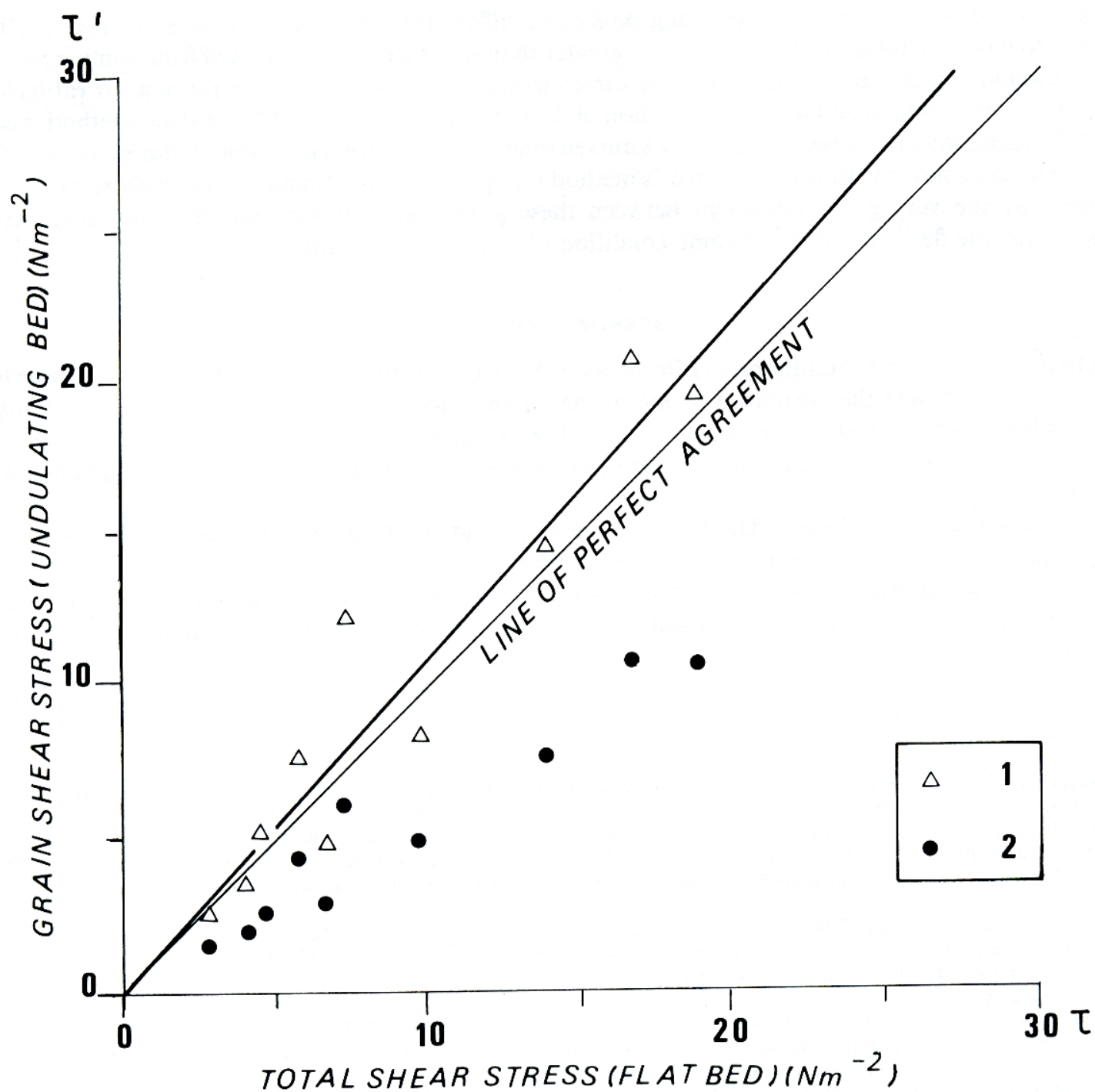

Figure 7. Relation between the total stress of the flat bed $(\tau)$ (Equation 1) and the grain shear stress $\left(\tau^{\prime}\right)$ evaluated for the undulating bed from Laursen method (1) and Meyer-Peter method (2); the line of regression is calculated from Laursen method data

total shear stress $(\tau)$. The application of the method where the ratio $n^{\prime} / n_{0}$ is introduced in Equation 3 yields values of grain shear stress very similar to that deduced by the Laursen method. Both methods give a ratio $\tau^{\prime} / \tau$ close to 1 , except when the dimensionless flow depth is low $\left(d / \mathbf{D}_{50}\right.$ less than 4$)$. In that case, $\tau^{\prime} / \tau$ is about $0 \cdot 75$. Indeed, there exists a microrelief produced by the irregularities of the bed which are due to the arrangement of the particles forming the bed and this could act like a bedform shear stress. However, following Rauws (1987), the use of this kind of method seems to be inappropriate at low values of relative submergence. This assertion is confirmed by the discrimination of 'large-scale roughness elements' produced by Bathurst et al. (1981) for a relative submergence close to 4 . But even if the values for lowest depth are somewhat undervalued, it appears from Figure 2 that the Laursen method gives a rather good evaluation of grain shear stress. On the other hand, the values calculated using the approach developed by Meyer-Peter are clearly lower. These results fit well with the conclusions of Singhal et al. (1980). Finally the relationship between the shear stress $\tau^{\prime}(=\tau)$ and that calculated from friction velocities is relatively good although the latter is systematically somewhat higher. 
When bedforms were created (alternating pools and riffles), the form shear stress is far from negligible. Contrary to flat beds, total shear stress is much greater than shear stress as calculated from friction velocities. The calculation of grain shear stress $\left(\tau^{\prime}\right)$ by the three methods previously tested, results in a $\tau^{\prime} / \tau$ ratio close to 0.40 for Laursen's method and for the application of the $n^{\prime} / n_{0}$ ratio, but for the Meyer-Peter method it is close to $0 \cdot 22$. The grain shear stresses evaluated by Laursen's method are well correlated with those calculated from friction velocities, showing thus that Laursen's method is appropriate to estimate the grain shear stress. This is confirmed by the very good agreement between these grain shear stresses and the total shear stresses calculated for the flat bed under the same condition of slope and discharge.

\section{ACKNOWLEDGEMENTS}

I wish to offer Professor A. Sundborg and Professor J. Norrman (University of Uppsala) my sincerest thanks for the cordial welcome they extended to me in their Laboratory, and likewise for the help and advice I received when conducting the experiments and writing this article.

I also wish to thank Professor J. Alexandre and Professor A. Pissart who read this article and offered their comments.

My thanks go also to Professor J. De Ploey, Dr J. Poesen, and Drs. G. Rauws (University of Leuven), for the fruitful discussions during the preparation of this article.

My stays in Sweden were made possible thanks to support from the 'Communauté Française de Belgique', the 'Fonds National de la Recherche Scientifique', and the 'Swedish Institute'. Heartfelt thanks to these organizations.

\section{REFERENCES}

Bathurst, J. C., Li, R. M., and Simons, D. B. 1981. 'Resistance equation for large-scale roughness, J. Hydraul. Div. ASCE, 107, $1593-1613$. Bogardi, J. 1974. Sediment transport in alluvial streams. Akademiai Kiado, Budapest.

Bray, D. I. 1979. 'Estimating average velocity in gravel-bed rivers', J. Hydraul. Div. ASCE, 105, 1103-1122.

Bridge, J. S. and Jarvis, J. 1982. 'The dynamic of a river bend: a study on flow and sedimentary processes', Sedimentol, 29-2, 499-541. Carling, P. A. 1983. 'Threshold of coarse sediment transport in broad and narrow natural streams', Earth Surf. Processes and Landforms, 8, 1-18.

Dietrich, W. E., Smith, J. D., and Dunne, T. 1979. 'Flow and sediment transport in a sand bedded meander', J. Geol., 87, $305-315$.

Einstein, H. A. and Barbarossa, N. L. 1952. 'Channel roughness', Am. Soc. Civil. Eng., 117, 1121-1132.

Govers, G. and Rauws, G. 1986. 'Transporting capacity of overland flow on plane and on irregular beds', Earth Surf. Processes and Landforms, 11, 515-524.

Hey, R. D. 1979. 'Flow resistance in gravel-bed rivers', J. Hydraul. Div. ASCE, 105, 365-379.

Johnson, J. W. 1942. 'The importance of considering side-wall friction in bed-load investigations', Civil Engineering, 12-6, 329-331.

Kamphuis, J. W. 1974. 'Determination of sand roughness for fixed beds', J. Hydraul. Res., 12-2, 193-203.

Kapdalsi, M. S. and Dyer, K. R. 1986. 'Threshold conditions for sand movement on a riffled bed', Geo-Marine Letters, 6, $161-164$.

Komar, P. D. and Li, Z. 1988. 'Applications of grain-pivoting and sliding analyses to selective entrainment of gravel and to flowcompetence evaluations', Sedimentol., 35, 681-695.

Laursen, E. M. 1958. 'The total sediment load of streams', J. Hydraul. Div., 1530, 36 pp.

Leopold, L. B. and Emmett, W. W. 1981. 'Some observations on the movement of cobbles on a streambed', Proc. Florence Symp. Erosion and Sediment transport measurement, 49-59.

Limerinos, J. J. 1970. 'Determination of the Manning coefficient from measured bed roughness in natural channels', Geol. Survey Water Supply, 1898-B, 47 pp.

Lisle, T. 1979. 'A sorting mechanism for a riffle-pool sequence', Geol. Soc. Am. Bull., Part II, 90, 1142-1157.

Meland, N. and Norrman, J. O. 1966. 'Transport velocities of single particles in bedload motion', Geog. Ann., 48A, $165-182$.

Petit, F. 1987. 'The relationship between shear stress and the shaping of the bed of pebble-loaded river', Catena, 14-5, 453-468.

Petit, F. 1988. 'Critical shear stress from experiments conducted in a pebble-bedded flume', Geog. Ann. (submitted for publication).

Petit, F. 1989. 'Evaluation of grain shear stresses required to initiative movement of particles in natural rivers', Earth Surf. Processes and Landforms (in press).

Rauws, G. 1987. 'The initiation of rills on plane beds of non-cohesive sediments', Catena Supl., 8, 107-118.

Richards, K. 1982. Rivers, Form and Process in Alluvial Channels., Methuen, London, 358 pp.

Simons, D. B. and Senturk, F. 1977. 'Sediment transport technology', Water Resources Publications, Fort Collins Colo, 807 pp.

Singhal, M. K., Mohan, J., and Agrawal, A. K. 1980. 'Role of a grain shear stress in sediment transport', Irrigation and Power, 37, $105-108$.

Vanoni, V. A. 1975. (Ed.). 'Sedimentation Engineering', Manuals and Reports on Engineering Practice, n ${ }^{\circ} 54$, Amer. Soc. of Civil. Eng. 